\title{
Relationship of platelet retention in glass bead columns to the rate of aggregation with adenosine diphosphate and thrombin
}

\author{
A. L. BLOOM AND E. P. EVANS \\ From The Institute of Pathology, Royal Infirmary, Cardiff
}

SYNOPSIS The initial rate of platelet aggregation induced by adenosine diphosphate and thrombines correlated with the number of platelets retained when samples of citrated blood from the same normal donors were passed through glass bead columns. The results support the view that the glass bead column method of measuring platelet 'adhesiveness' is influenced by platelet aggregation $\vec{\infty}$

Platelet adhesiveness and aggregation are important because of their probable role in haemostasis and thrombosis. Platelet adhesiveness is often measured by determining the proportion of platelets removed during controlled exposure of blood to glass. These methods, however, may measure not only adhesion to glass but also platelet-to-platelet adhesion on the surface of the glass or merely the filtration of platelet aggregates by the glass surfaces (Salzman, 1963; Pitney and Potter, 1967). Hellem (1960) found that platelet retention in a glass bead column was enhanced by a constituent of red cells. This was also shown to cause platelet aggregation and was later identified as adenosine diphosphate (ADP) (Gaarder, Jonsen, Laland, Hellem, and Owren, 1961). Haslam (1964) suggested that ADP might also mediate the platelet aggregation induced by thrombin. Bloom and Davies (1967) showed that in citrated blood changes in the number of platelets retained in glass bead columns, occurring within 30 minutes of the addition of ADP, coincided with the appearance or dispersal of platelet aggregates. A quantitative relationship between platelet retention in glass bead columns and aggregation has not, however, been firmly established. In the present study it will be shown that there is a positive correlation between the initial rate of aggregation induced by ADP and thrombin and the degree of platelet retention in glass bead columns.

\section{METHODS}

Blood was collected from normal volunteers using

Received for publication 31 January 1969. plastic syringes and mixed with $3.8 \% \mathrm{w} / \mathrm{v}$ trisodium citrate in the proportion of 9 parts of blood to 1 part of citrate. The citrated blood was rotated at room tem-s perature on a Matburn mixer at $40 \mathrm{rpm}$ for five minutese before the experiments. Platelet retention or 'adhesive $\square$ ness' was measured by a modification of the method of Hellem (1960). A sample of blood of $4 \mathrm{ml}$ was transferreds to a plastic syringe and passed through a column of glasso beads at constant speed by means of a Sage syringe pump.응 The time taken for the blood to pass through the columna was 74 seconds and the leading edge traversed the column in 16 seconds. The columns were constructed of 3 Portex polyvinyl tubing $14.0 \mathrm{~cm}$ long and $4.0 \mathrm{~mm}$ dia meter. They were filled with $3.4 \pm 0.03 \mathrm{~g}$ of glass beads 0.452 to $0.520 \mathrm{~mm}$ diameter (Jencons, grade 8). The effluent blood was collected into plastic containers containing the dried dipotassium salt of EDTA. Platelet: counts were performed by a visual method (Baar, 1948) before and after passage of blood through the columns. The difference between the counts indicated the number of retained platelets and this was expressed as a percentage of the original platelet count. The number of red은 cells lysed during passage of blood through the columns $D$ was calculated by estimating the whole-blood haemoglobin content (standard cyanmethaemoglobin method) and the red count (Coulter counter model D) of the affluent bloodur together with the plasma haemoglobin content of ther effluent blood (Fielding and Langley, 1958).

Platelet aggregation was measured by a method similar to those of Born (1962) and O'Brien (1962). Platelet-rich plasma was obtained by centrifuging citrated blood ato $1,400 \mathrm{rpm}$ for six minutes. It was adjusted with platelet-市 poor plasma from the same donor to a count of $340,000 \stackrel{\leftrightarrow}{+}$ per $\mathrm{cmm}$, and $2 \mathrm{ml}$ was placed in the cuvette of a modified $\square$ EEL titrator maintained at $37^{\circ} \mathrm{C}$. It was mixed at constantō speed by means of a magnetic stirrer and changes in light $\vec{\Phi}$ transmission due to aggregation were recorded with $a_{\mathbb{D}}$ Servoscribe potentiometer. The aggregating agents used을 


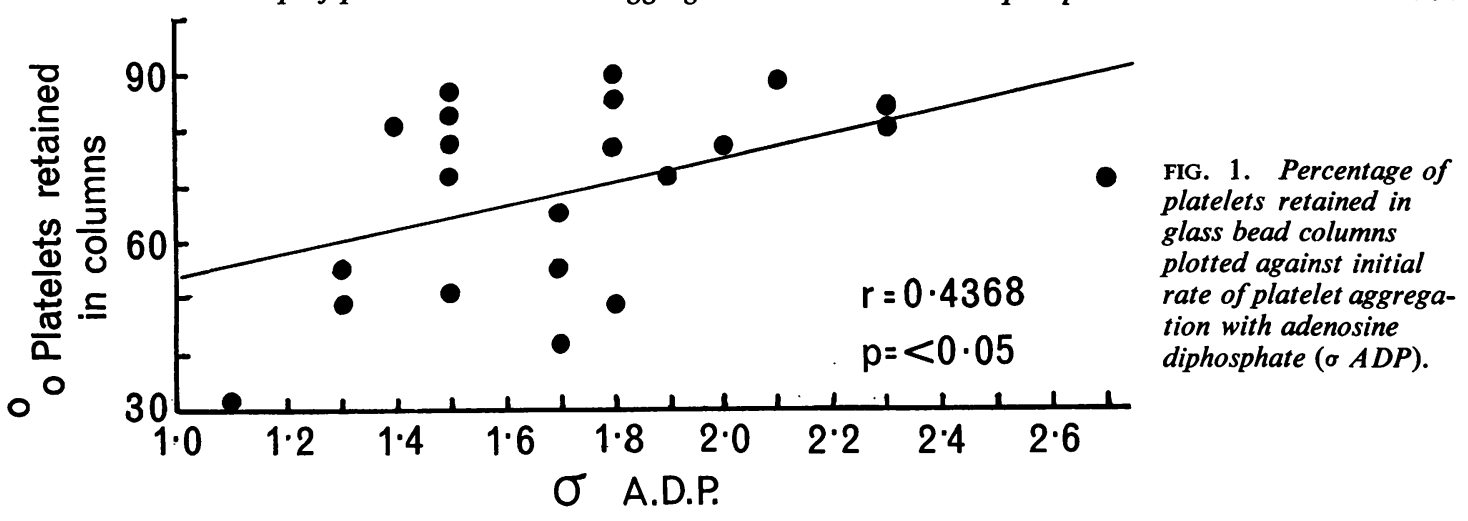

were ADP (Sigma), $0.05 \mathrm{ml}$, to give a final concentration of $5 \times 10^{-5} \mathrm{M}$, and human thrombin (Fibrindex, Ortho), $0.05 \mathrm{ml}$, to give a final concentration of $0.25 \mathrm{IU}$ per $\mathrm{ml}$. The rate of aggregation $(\sigma)$ was calculated from the aggregation curves by the method of Holdrinet, Ewals, and Haanan (1968). The onset of aggregation could be accurately determined so the values for $\sigma$ were calculated from the aggregation curves and not, as by Holdrinet et al, from those of disaggregation. The formula used was $\sigma=-\ln t_{a} / t_{\max }$, where $t_{\max }$ was the time taken to attain maximum change of optical density, and $t_{\mathrm{a}}$ was the time taken to attain 0.6 of the maximum change. Higher values for $\sigma$ indicated a greater initial rate of platelet aggregation. Twenty-two samples of normal blood were studied but in a few instances insufficient was obtained to perform all the studies.

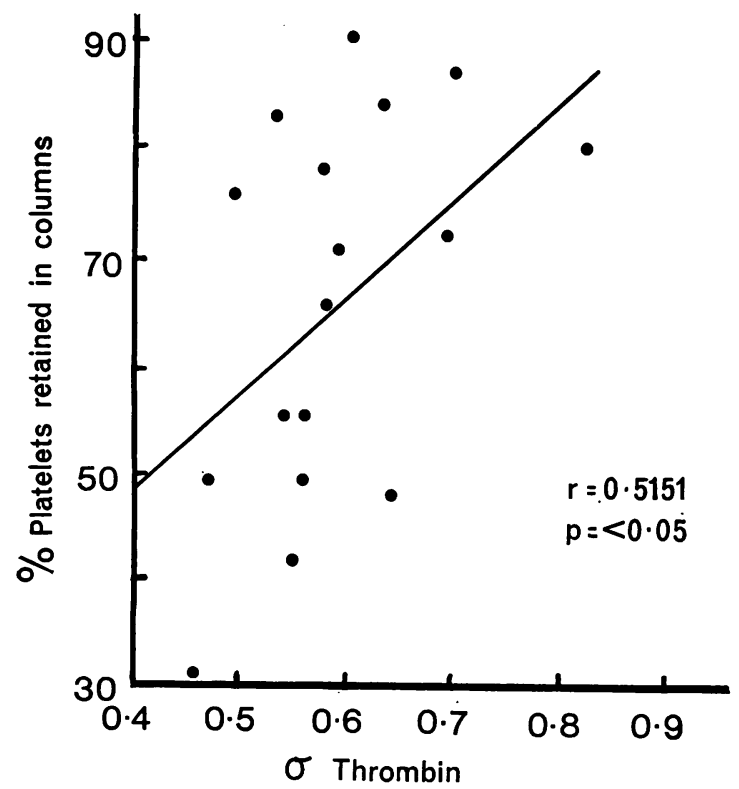

FIG. 2. Percentage of platelets retained in glass bead columns plotted against initial rate of platelet aggregation with thrombin ( $\sigma$ thrombin).

RESULTS

Platelet retention by this method ranged from $30 \%$ to $90 \%$ with a mean of $69 \%$ (SD 18). The rate of aggregation with ADP ( $\sigma$ ADP) varied from 1.1 to 2.7 with a mean of 1.7 (SD 0.37 ). The rate of aggregation with thrombin ( $\sigma$ thrombin) varied from 0.45 to 0.81 with a mean of 0.58 (SD 0.09). In Figs. 1 and 2 the percentage platelet retention is plotted against the rate of aggregation with ADP and thrombin. In both instances there is a statistically significant positive correlation showing that the extent of platelet 'adhesion' or retention in the glass bead columns is related to the initial rate of platelet aggregation with ADP and thrombin.

No significant relationship was detected between the percentage of retained platelets and the number of red cells lysed during passage of blood through the glass bead columns.

\section{DISCUSSION}

The mechanism of platelet removal by glass in adhesion experiments has not been firmly established. Johnson, Fredell, Shepard, Tebo, Chang, Pederson, and Van Horn (1967) flushed their glass bead columns with formalin and detected many platelet aggregates but no singly adhering platelets. Increased ADP concentration was detected in the effluent blood. It seems likely that platelet-to-platelet adhesion or aggregation were major factors influencing the removal of platelets. The observation by Hellem, Ödegaard, and Skalhegg (1963) that the addition of ADP increases platelet retention in glass bead columns is also consistent with this view. In our experiments platelet retention has been correlated with the initial rate of aggregation rather than with the final change of optical density. Blood passed relatively rapidly through the glass bead columns. If platelet aggregation occurred due to ADP liberat $2 d$ 
into the blood it is the rate of aggregation which would be likely to correlate with the number of retained platelets. This in fact proved to be the case and the evidence thus supports the hypothesis that this technique for measuring adhesiveness is influenced by aggregation. Further support for this view comes from the observation of O'Brien and Heywood (1967) that whilst a normal calcium concentration is necessary for most platelet-glass interactions, platelet aggregation is not grossly impaired by citrate. If this is correct, platelet aggregation rather than adhesion to glass was more likely to have influenced the retention of platelets when citrated blood was passed through glass bead columns in the present study.

Studies of the action of thrombin on platelets have shown that it not only causes aggregation but also releases certain platelet contents, including adenine nucleotides (Born, 1958). According to Karpatkin (1967), thrombin and ADP, both of which cause platelet aggregation, also induce increased platelet glycolytic flux and expenditure of adenosine triphosphate. These findings suggest that a similar mechanism may be responsible for ADP- and thrombin-induced aggregation. This may explain our observation that the initial rate of aggregation by both ADP and thrombin correlated with the percentage of platelets retained in the glass bead columns.

Although aggregation caused by ADP liberated from red cells may affect the number of platelets retained in glass bead columns the latter did not correlate with the number of red cells haemolysed. Pitney and Potter (1967) have noted that retention 0 of platelets in such columns did not correlate with the haematocrit of the filtered blood. It is possible $\frac{\bar{\omega}}{\partial}$ that ADP was liberated from other blood com- $\mathbb{\mathbb { D }}$ ponents, such as white cells, or from the platelets themselves. It also seems likely, however, that the rate of aggregation or extent of platelet retention. in glass bead columns depends not only on the action of an aggregating agent but also on the reactivity of $\stackrel{\rho}{\omega}$ the platelets and the concentrations of certain plasma 용 components such as fibrinogen which are known to i influence these platelet functions.

\section{REFERENCES}

Baar, H. S. (1948). J. clin. Path., 1, 175.

Bloom, A. L., and Davies, A. J. (1967). Ibid, 20, 706.

Born, G. V. R. (1958). Biochem. J., 68, 695

- (1962). Nature (Lond.), 194, 927.

Fielding, H. E., and Langley, P. E. (1958). Amer. J. clin. Path., 30, 528. Gaarder, A., Jonsen, J., Laland, S., Hellem, A., and Owren, P. A. (1961). Nature (Lond.), 192, 531.

Haslam, R. J. (1964). Ibid, 202, 765.

Hellem, A. J. (1960). Scand. J. clin. Lab. Invest., 12, suppl. 51.

, Odegaard, A. E., and Skalhegg, B. A. (1963). Thrombos. Diathes. haemorrh. (Stuttg.), 10, 61 .

Holdrinet, A., Ewals, M., and Haanan, C. (1968). Lancet, 1, 1150.

Johnson, S. A., Fredell, L., Shepard, J. A., Tebo, T. H., Chang, C., Pederson, H. J., and Van Horn, D. L. (1967). In Physiology of Hemostasis and Thrombosis, edited by S. A. Johnson and W. H. Seegers. C. C. Thomas, Springfield, IIl. p. 44.

Karpatkin, S. (1967). J. clin. Invest., 46, 409.

O'Brien, J. R. (1962). J. clin. Path., 15, 452. , and Heywood, J. B. (1967). Ibid, 20, 56

Pitney, W. R., and Potter, M. (1967). Ibid, 20, 710.

Salzman, E. W. (1963). J. Lab. clin. Med., 62, 724. 